\title{
SIMULATION MODELLING POSSIBILITIES IN TEACHING ECONOMIC PROCESSES
}

\author{
Peter Grabusts \\ Rezekne Academy of Technologies, Latvia
}

\begin{abstract}
For the purpose of simulation models visualization of various economic disciplines, it is appropriate to use specialized programs that allow to characterize the nature of a particular model, but also make it possible to carry out a simulation model based on various parameters. This article substantiates the usefulness of introduction the simulation models at the initial research process, when simulation models can be imported parallel with analytical relations acquisition. Series of research were carried out in order to demonstrate the suitability of the Matlab Simulink for the purpose of visualization of various simulation models of various economic disciplines. Often, the analytical solution is much simpler than the visual Simulink model, but in the perspective of training purposes, it gives an understanding of the usefulness of such models. In the research part of the study the modelling capabilities in economic studies were demonstrated- adapted models in optimal tax rates computing and equilibrium determination in the competitive market.
\end{abstract}

Keywords: education, Matlab Simulink, modelling, simulation, visualization.

\section{Introduction}

The classification of the general economic models is based on the scope of the economic system under study. From this perspective, the models can be divided into three major groups: the model of firms, industry models and macroeconomic models.

The model should be based on solid empirical basis. However, this information is usually not available for the creators of economic models. The management of the companies simply do not want to provide the details about the activities of their businesses to the third person. This is especially true for the companies working in the face of strong competition.

There are difficulties in constructing an adequate numerical model of the company due to the fact that such a model should be based on a deep knowledge of the real decision-making processes in organizations. To do this, it is necessary to be aware of the current state of such disciplines as decision-taking theory, organization theory, and understand the issues of psychology, sociology, politics, production management and economics as well. 
The aim of the study of different simulation models is the formation students' theoretical knowledge and practical skills in the use of simulation modelling techniques in research of solving specific problems in programming and modelling of real applications - matrix algebra, solving of equations, economics applications. During the course students get acquainted with the means of simulation modelling processes of functioning systems, master the simulation modelling methods and typical stages of modelling process that form the" sequence": the construction of the conceptual model and its formalization - model algorithmization and its computer implementation - simulation experiment and interpretation of the results of the modelling; acquire practical skills for implementation of modelling algorithms for studies of characteristics and behaviour of complex economic systems (Kay, 1984; Karel \& Tomas, 2015).

Simulation modelling - the most powerful and versatile method for studying and evaluating the effectiveness of systems the behavior of which depends on the influence of random factors.

The implementation of such opportunities in the universal programming language is a difficult task. Currently, there are quite a lot of software, that allow to model processes. However, now there is a product that allows to solve these problems quite effectively - MATLAB packet (Kiusalaas, 2016; Siauw \& Bayern, 2015; Smith, 2013) containing visual simulation tool - Simulink. Simulink - a tool that allows you to simulate the system quickly, get the indexes of expected effect and compare them with the amount of effort required to achieve them (Karel \& Tomas, 2015; Xue \& Chen, 2013).

The aim of the article is to show Matlab Simulink suitability for the purpose of visualizing simulation models of various economic disciplines (Grabusts, 2016). To reach the aim, the following research tasks have been set: identification of Matlab Simulink possibilities for simulation of economic processes; demonstrate visualization models on the basis of examples. The article presents examples of using simulation modelling in the economic research processes optimal tax rate searching and modelling market equilibrium price. Common research methods are used in this research: descriptive research method, statistical method, mathematical modelling.

\section{Matlab Simulink and possibilities of visual simulation}

Of particular interest for simulation is a Simulink tool designed specifically for modelling dynamical systems. It has a library of standard graphics units with built-in mathematical functions. It is sometimes called a tool of visual modelling (Shiflet \& Shiflet, 2014; Silva, 2009).

The system has a library of graphical blocks with built-in mathematical functions. Although Simulink is used to solve engineering and scientific-technical 
problems, the possibilities of its use are almost unlimited. Initial parameters are input interactively by graphics setting of elementary blocks circuit compounds, resulting in a model of the studied system. The blocks included in the model relate to each other both in information and in management. The type of connection depends on the type of the block and the logic of the model.

Simulink program is an application to the MATLAB package. When simulation using Simulink is implemented, the principle of visual programming is realized, according to which the user on the screen creates a model of device, process or system, and performs calculations from the standard blocks of the library. At the same time, in contrast to the classical ways of modelling, the user does not need to study the programming language and numerical methods of mathematics thoroughly but some general knowledge is required when working on the computer, and, of course, knowledge on the subject area in which he operates.

Thus creating a model and launching it, it is possible to observe the results of simulation. In the simulation the user can choose the method of solving the equations, and the way of changing the model time. During the simulation it is possible to monitor the processes happening in the system. To this purpose special viewing devices, that are part of the Simulink library, are used. The results of simulation may be presented in the form of graphs.

Series of research were carried out in order to demonstrate the Simulink suitability for simulation model visualization purposes in different economics disciplines. It should be noted that often the analytical solution is much simpler than the visual Simulink model, but in perspective it gives an understanding of such models usefulness.

Fig. 1 shows the used blocks' description and its explanation given in the examples.

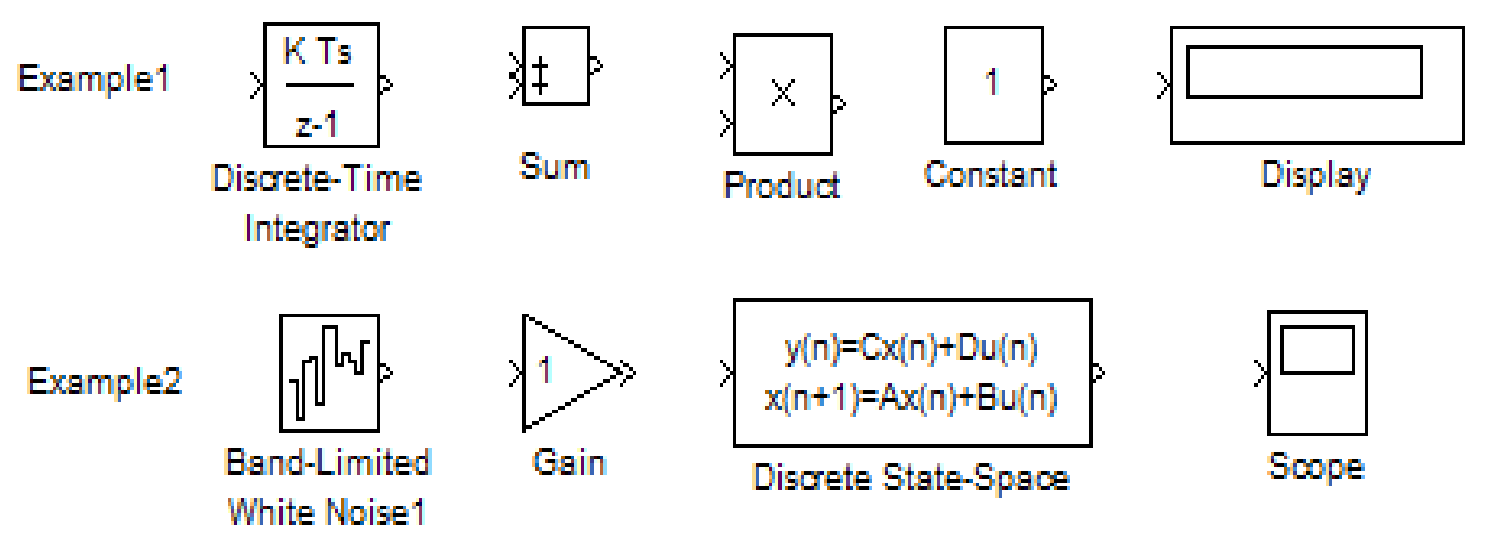

Figure 1 Blocks used in the examples 
The Discrete Time Integrator block (Commonly Used Blocks) performs discrete-time integration or accumulation of a signal. We use this block in discrete- time systems instead of the Continuous Integrator block in continuous-time systems. The block can integrate or accumulate using the Forward Euler, Backward Euler, and Trapezoidal methods.

The Product block (Commonly Used Blocks) block performs multiplication or division of its inputs. This block produces outputs using either element-wise or matrix multiplication, depending on the value of the Multiplication parameter.

The Sum block (Commonly Used Blocks) performs addition or subtraction on its inputs. This block can add or subtract scalar, vector, or matrix inputs.

The Constant block (Sources) is used to define a real or complex constant value.

The Display block (Sinks) shows the output value at the end of the simulation time.

The Band Limited block (Sources) is an implementation of white noise into Zero-Order Hold block.

The Gain block (Commonly Used Blocks) multiplies the input by a constant value (gain). The input and the gain can each be a scalar, vector, or matrix. We specify the value of the gain in the Gain parameter.

The Discrete State-Space block (Discrete) implements the system described by the equations: $x[n+1]=A x[n]+B u[n] y[n]=C x$.

\section{Research part}

\section{Example 1. Optimal Tax Rate searching}

The aim of the experiment: to study the dependence of budget revenues on the tax rates. The author modified the (Cisar, 2004) study results.

The state announces the income tax rate and receives funds from the companies to the budget. Companies have their own capital, get profit, and pay funds to the budget according to the tax rate. After-tax profit as retained earnings is fully included in the company's own capital. Dividends are not paid out, no other deductions from income are done. All profit is divided only into two flows: to the budget and the rest-to the equity.

Budget revenues for a certain period of time will be the greatest not at the maximum but at the optimum tax rate for the budget. That is, with the growth of the tax rate, the revenues to the budget will increase and then decrease.

The amount of tax revenues from enterprises for the simulated period is stored in the fiscal accounts, and is represented by the integral:

$$
\mathrm{BD}(\mathrm{t})=\int_{-\mathrm{t}=\mathrm{tb}}^{-\mathrm{t}=\mathrm{tf}} \mathrm{PRF}(\mathrm{t}) * \mathrm{TXRT}^{*} \mathrm{dt}
$$


where $B D(t)$ - amount of funds received in the budget from the beginning of the simulation till the moment $\mathrm{t}$, euro;

$P R F(t)$ - pretax profit, derived by an enterprise at the moment $\mathrm{t}$, euro/year.;

$T X R T$ - income tax rate;

$t$ - current time, year.

$t b$ - beginning moment of simulation;

$t f$ - final moment of simulation.

A profit balance capitalized by an enterprise during the simulation time:

$$
\mathrm{CP}(\mathrm{t})=\int_{-\mathrm{t}=\mathrm{tb}}^{-\mathrm{t}=\mathrm{tf}} \operatorname{PRF}(\mathrm{t})^{*}(1-\mathrm{TXRT})^{*} \mathrm{dt}
$$

Profit at time $t$ :

$$
\operatorname{PRF}(\mathrm{t})=\mathrm{CP}(\mathrm{t}) * \mathrm{RN}
$$

where $R N$ - profitability of the enterprise capital. It is set as a parameter of the enterprise, initial data.

The model of such a process is shown in Fig. 2.

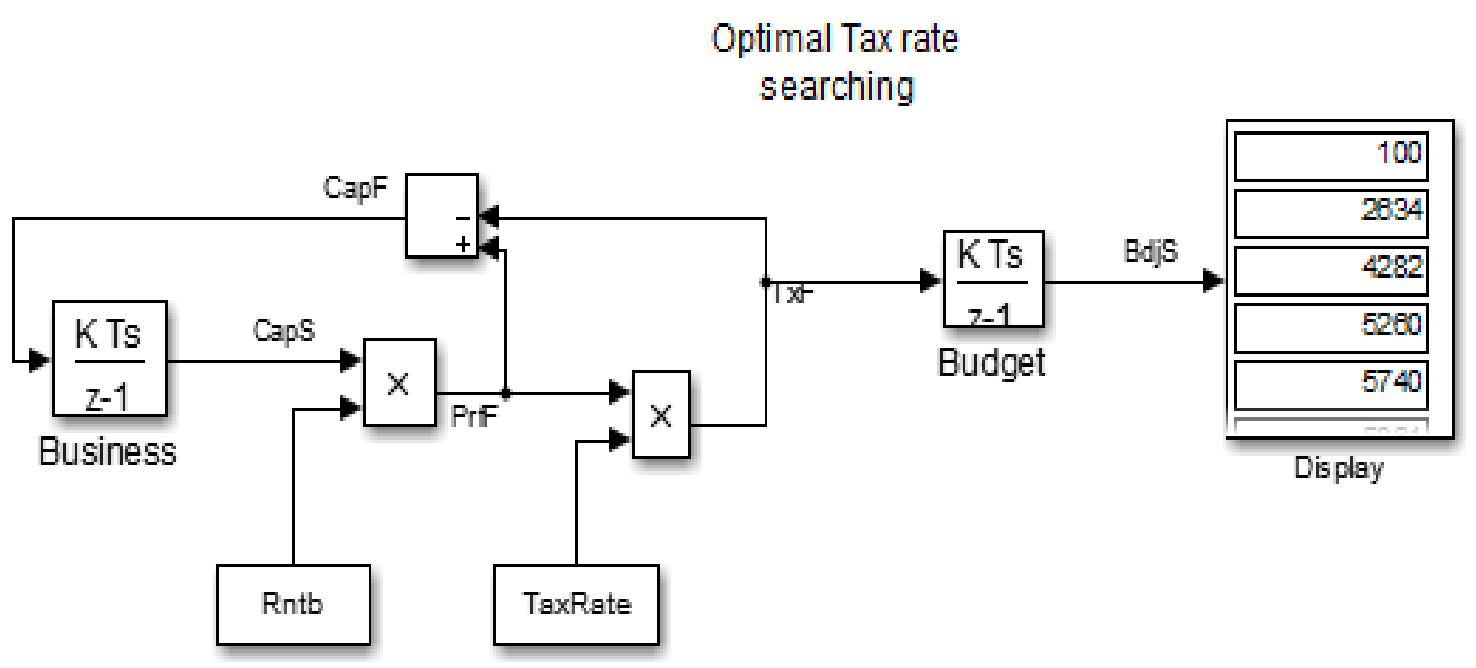

Figure 2 Optimal tax rate searching model

In the scheme block Business, there is presented the hoarder of the equity of the enterprise, it is taken from the library of elements as a block Integrator of discrete time. The investment flow CapF enters on the block input. It is aftertax, retained profit. It is accumulated by a business and increases its equity capital. Block Out - is the amount of capital in business CapS. Profitability is defined by a block with the name Rntb. The next block works out the multiplication of the profit flow on the tax rate Tax Rate. This is the flow of deductions from profits to the state budget TxF. The tax rate is set with the name Tax Rate. The block Budget is represented by the integrator. It accumulates tax revenues $\mathbf{T} \mathbf{x F}$ for the 
simulation period as a variable BdjS. The block Display reflects numerical values of BdjS.

The optimal tax rate modelling result is shown in Fig. 3.

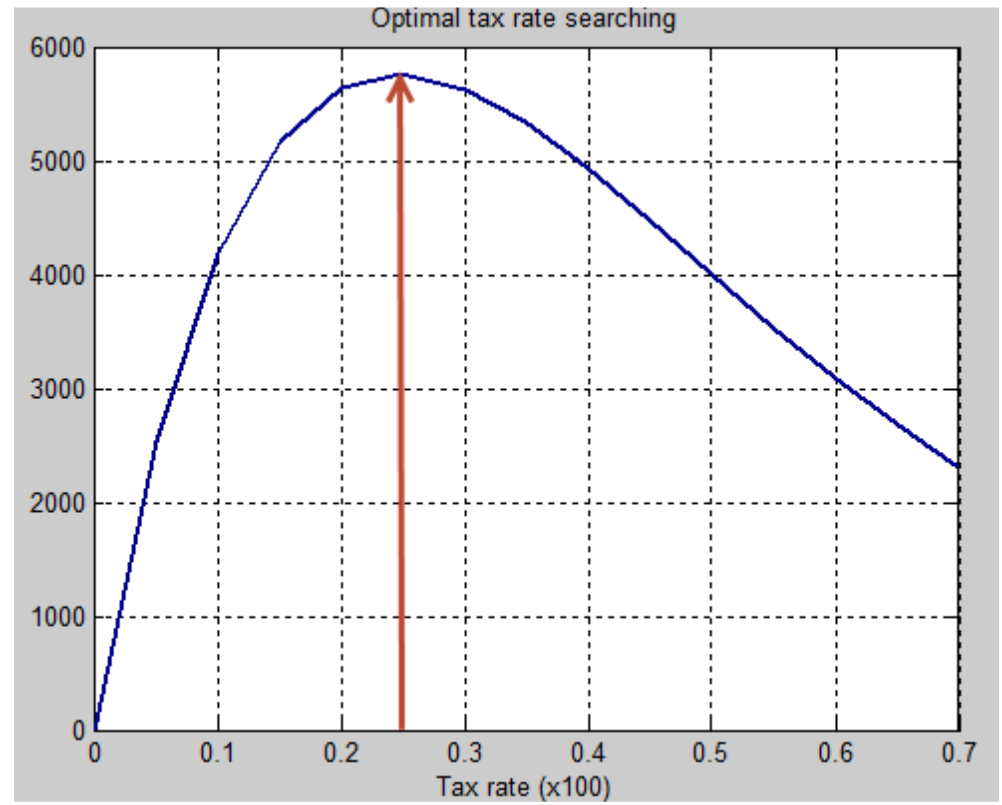

Figure 3 Optimal tax rate

With increasing rate, the revenues to the budget increase and then decrease. There is a strongly marked maximum, i.e., the optimal tax rate for the budget. The higher the profitability of the enterprise is, the more pronounced the optimal tax rate is. With the growth of the profitability, the optimal rate is reduced (shifted to the left), aiming at a fixed value, on our charts, approximately, to $23-25 \%$.

Example 2. Model of market equilibrium price

In economic theory it is considered that he price is set by the interaction of supply and demand.

Suppliers deliver goods to the market. The higher the market price, the more suppliers and goods. Consumers buy goods. The lower the price, the more customers and purchases. Goods on the market are characterized by two parameters: quantity and price. In this research author modified the (Cisar, 2004) study results.

For the initial study a very rough model is selected: linear, without reserves, chances, forecasts, and other factors.

Function of dependence demand on price

where -

$$
D m d=D 0-K d * P r c
$$

Dmd - demand for the current time interval;

$D 0$ - demand at zero price; 
$K d$ - the slope of the demand line;

PrC - price of the goods.

The line of dependence supply on price

where -

$$
S p l=S 0+K s * \operatorname{Prc}
$$

$S p l$ - supply for the current time interval;

$S 0$ - offer at zero price;

$K s$ - the slope of the demand line;

Prc - price of the goods.

A block diagram of the simulation model in Simulink looks as follows (see Fig. 4).

\section{Market equilibrium}

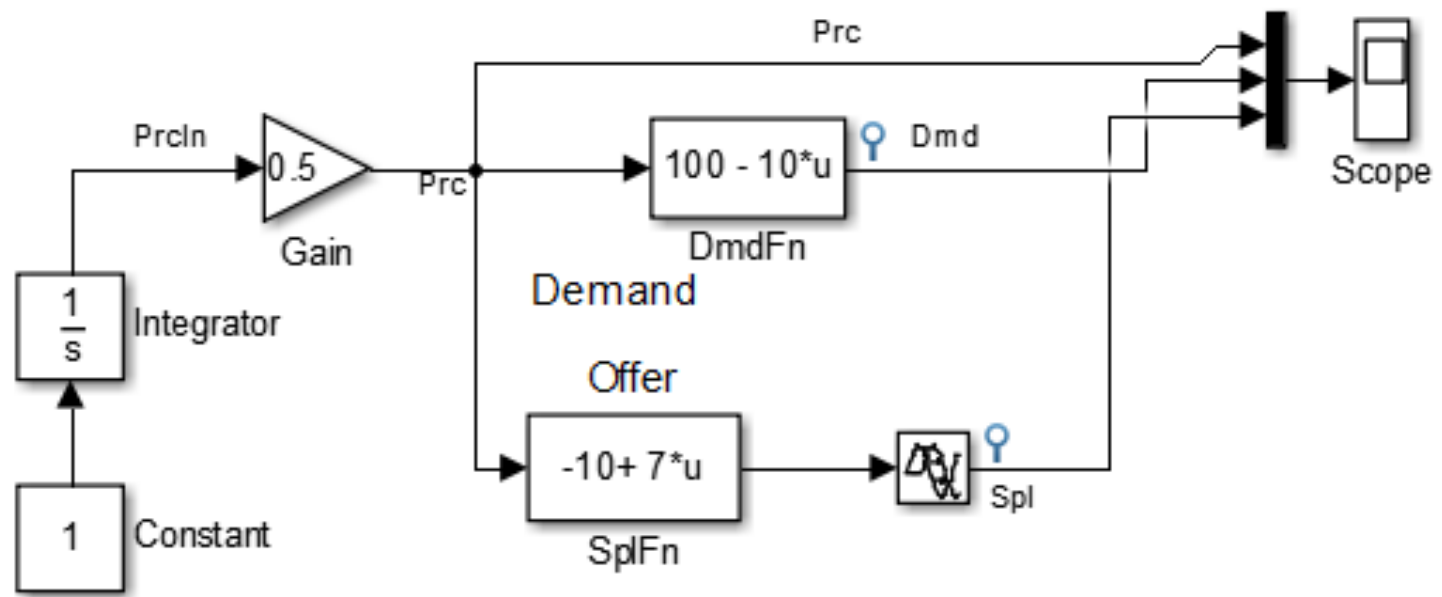

Figure 4 Block diagram of Simulation model

Demand is represented by a single block called DmdFn. It calculates the demand value based on the prices supplied to the input unit.

Symbols and unit settings on the following scheme:

$$
u=\operatorname{Prc}, D 0=100, K d=10 .
$$

The offer is represented by three building blocks. The function of dependence the amount of goods offered for sale on the price is realized by block named SplFn. It calculates the value of the offer, depending on the prices supplied to the input unit.

Block symbols and parameters on the scheme are following:

$$
u=\operatorname{Prc}, S 0=10, K s .=7 .
$$


The seller delivers the goods in the amount of $\mathbf{S p l}$, defined on the basis of the price of last period of time. SplFn block simulates a solution of a supplier to accept the price of the current demand. He agrees to sell all the goods at a price that the demand line dictates. The block implements the function which is opposite of demand function and calculates the price Prc, at which supplier will be able to buy all the goods Spl. Block Parameters are identical with parameters of the block Demand DmdFn.

The results of modelling are shown in Fig. 5.

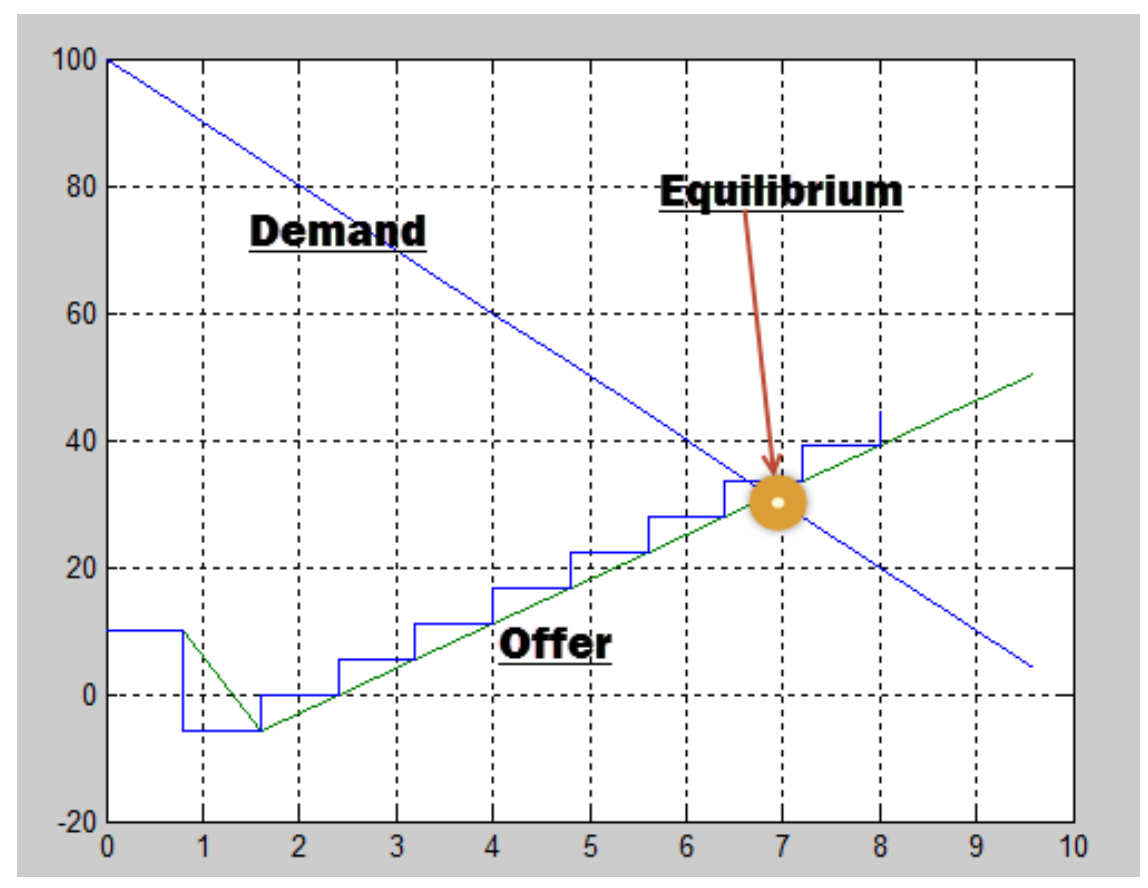

Figure 5 Results of modelling

As result of modelling it can be stated that in theory, at some period of time, the equilibrium between demand and supply was established. Of course, this model is very rough, but it gives an idea of the possibilities of Matlab Simulink in economic or other scientific processes simulation (Anderson, 2005; Cerný, 2009; Chapra \& Canale, 2015; Esfandiari, 2013; Karris, 2006).

\section{Conclusions}

In the article there is a substantiation of the usefulness of simulation model implementation for the initial teaching process when acquiring the analytic relationship for modelling purpose, the simulation models can also be imported. This makes it possible to perceive not only the possibilities of using formulas, but also to visualize the different correlations in graphical form. 
In the research part the possibilities of simulation modelling for economic studies are demonstrated - optimal tax rate searching and market equilibrium modelling. Of course, these examples can be realized easier, but the use of simulation models make it possible to raise learners' horizon and gives an idea of the potential options of using such models.

As a whole, it can be concluded that Matlab Simulink tool is very suitable not only for engineering calculations, but also can serve as a simulation model visualization tool in different economic applications.

\section{References}

Anderson, P. L. (2005). Business Economics and Finance with MATLAB®, GIS, and Simulation Models. Chapman \& Hall.

Cisar, I. (2004). Simulink for economists, for Mathworks.Inc.

Cerný, A. (2009). Mathematical Techniques in Finance: Tools for Incomplete Markets, $2 e$. Princeton University Press.

Chapra, S. C., \& Canale, R. P. (2015). Numerical Methods for Engineers, 7e. McGraw-Hill.

Esfandiari, R. S. (2013). Numerical Methods for Engineers and Scientists Using MATLAB. Chapman \& Hall/CRC.

Grabusts, P. (2016). Visualization Capabilities of Simulation of Economic Processes. Latgale National Economy Research, Journal of Social Sciences, No. 1 (8), 20-30.

Kay, C. (1984). Mathematics for Computer Programmers. New Jersey: Prentice Hall.

Karel, P., \& Tomas, Z. (2015). Multimedia Teaching Aid for Students of Basics of Control Theory in Matlab and Simulink. Procedia Engineering, Volume 100, 150-158.

Karris, S. T. (2006). Introduction to Simulink ${ }^{\circledR}$ with Engineering Applications. Orchard Publications.

Kiusalaas, J. (2016). Numerical Methods in Engineering with MATLAB, 3e. Cambridge University Press.

Shiflet, A. B., \& Shiflet, G. W. (2014). Introduction to Computational Science: Modelling and Simulation for the Sciences, $2 e$. Princeton University Press.

Siauw, T., \& Bayern, A. (2015). An Introduction to MATLAB Programming and Numerical Methods for Engineers. Academic Press.

Silva de, C. W. (2009). Modelling and Control of Engineering Systems. CRC Press, Inc.

Smith, D. (2013). Engineering Computation with MATLAB, 3e. Pearson Education Inc.

Xue, D., \& Chen, Y. (2013). System Simulation Techniques with MATLAB and Simulink. John Wiley \& Sons, Inc. 